detection of high-energy radiations. This discussion indicates the general principles of the phosphor crystal radiation-detector, and its uses and limitations for counter purposes. The article should prove a useful starting-point to those concerned with improving the performance and reliability and the range of applications of the scintillation-counter. The random motion of free electrons in a conductor or the emission of electrons by the cathode of a vacuum tube gives rise to those spontaneous fluctuations of electricity now generally known as 'noise'. In an article on fluctuation phenomena, A. van der Ziel reviews the Fourier analysis of the subject and the application of the phenomena to various generators, including vacuum and gas-discharge tubes, and crystal diodes and transistors. The scope of the subject covered is perhaps indicated by the fact that the list of references at the end of the contribution includes ten books, seven review papers and some ninety original papers. The subject of electronic digital computers is next dealt with by C. V. L. Smith, who reviews the recent development of highspeed automatically sequenced computers. 'This article includes a description of the machines developed in the United States known as 'Whirlwind', with its special electronic storage tube, and 'SEAC', which at present uses mercury line storage but is so constructed as to permit the later incorporation of cathode-ray-tube storage on the principles developed by F. C. Williams in Great Britain. The magnetron valve again receives attention in this series with a very practical paper entitled modulation of continuous-wave magnetrons, by J. S. Donal, jun. The last two papers in Vol. 4 also strike a more practical and novel note in dealing with, respectively, the magnetic airborne detector, by W. E. Fromm, and multi-channel radio telemetering, by $M$. G. Pawley and W. E. Triest. The development of both these subjects originated during the Second World War; but it is clear that there are civil applications of the instruments and techniques described, and it is most useful to have these reviews of the progress made during the past decade.

In most cases the contributions in both volumes are accompanied by a selected bibliography which will be valuable in guiding the research student to more detailed knowledge where he desires to seek it. The volumes are very well presented in a uniform style, and there is no doubt that the editor and his advisory board are rendering a great service to the scientific community in presenting this series, which will find an important place on our bookshelves.

R. L. Smith-Rosi

\section{ECONOMIC PLANTS OF THE WORLD}

\section{Economic Botany}

A Textbook of Useful Plants and Plant Products. By Albert F. Hill. (McGraw-Hill Publications in the Botanical Sciences.) Second edition. Pp. xii +560 . (London: McGraw-Hill Publishing Co., Ltd., 1952.) 59s. $6 d$.

GVERYTHING that helps towards a fuller H realization and better understanding of our dependence on the plant world is of value to-day, and the second edition of Dr. A. F. Hill's wellknown book will therefore be welcomed not only for itself but also for its considerable contribution towards this end.

The book may be described, like its predecessor, as an invaluable compendium of useful information about useful plants, presented in a way which, though perhaps a little staccato for some tastes, is both direct and simple. In general form it closely repeats the first edition, but it has been brought generally up to date and particularly so with regard to such matters as rubber, antibiotics, artificial fibres, new drugs and so on. A noteworthy addition is a very clear diagram illustrating the modern chemical utilizations of wood.

It is the easiest thing in the world to reproach a book for not being what its author never intended it to be, and Dr. Hill makes it plain that he does not essay to deal with many of the economic and social problems of his subject; but it must nevertheless bo admitted that the first pages of the introductory chapter, which is entitled "The Importance and Nature of Plant Products", do something less than justice to the rest of the book. There is a certain bleakness about them, and a slightly more humanistic approach would not only help to illumine the main body of the book, but would also put into truer perspective some of the author's comments on certain agricultural policies and practices. Similarly, in the new preface the emphasis is on plants as strategic materials rather than on their significance as one of the potential ultimate sources of world prosperity and tranquillity. It is this emphasis again, perhaps, that accounts for the rather unexpected order of treatment in the main text, which, beginning with the industrial plant-products such as fibres, wood, rubber and the rest, goes on then to drugs and leaves food supplies until the last. But as regards this book, these are matters of form rather than substance; and although they may involve some difference of opinion, they do not detract from the achievement in Dr. Hill's valuable work. It is a book which claims a rightful place not only in every botanical library but in many others also.

RONALD ĆOOD

\section{SCIENCE APPLIED TO FOOD}

Food Science

A Symposium on Quality and Preservation of Foods. Edited by Dr. E. C. Bate-Smith and T. N. Morris. Pp. xvii $+319+17$ plates. (Cambridge: At the University Press, 1952.) 40s. net.

$7 \mathrm{O}$ the scientific worker concerned with the study of food this book is of particular interest and value in that it deals mainly with the chemistry and biology of food materials, with little ordinary technological matter.

The book is, as the editors state, "a collection of lectures by contributors each of whom is an authority in his own field", and is not offered as a comprehensiv $\theta$ text-book of food science. It is such study of the fundamentals of food science that is properly the function of the State-owned research stations-and this aspect is a predominant feature in these lectures, which give clearly and concisely a record bringing up to date our scientific knowledge of the subjects discussed. The contributions are written in a simple, logical and direct manner, and the information is given briefly yet with adequate explanation. The style of composition is pleasing and is the same in all 